\title{
Factors Affecting the Performance of Micro and Small Enterprises in Diredawa City Administration
}

\author{
Abiy Serawitu \\ Dire Dawa Management and Kaizen Institute, Dire Dawa, Ethiopia
}

\begin{abstract}
This research aims to investigate and rank the influence of factors that affecting the performance of MSEs on wood and metal, garment, food processing and shoe and leather sectors in the case on manufacturing small enterprises in Dire dawa city administration. For the sake of achieving the objectives of this study, likert -scale type and multiple choice questionnaires was analyzed using appropriate host of statistical methods such as descriptive and inferential analyses. The information assembled through questionnaire from a population of 42 small manufacturing enterprises and face-to-face interview for 20 representative or owners of the enterprises. The empirical study elicited eight major challenges which seem to affect performance of manufacturing small enterprises in city. Descriptive findings revealed that marketing, working premises and financial factors respectively were found the three top most severe problems that challenged the MaSEs sector in GTP1 period. Similarly, the inferential analyses output also indicated that marketing, working premise, finance and technological factors are the decisive determinants for the performance of MaSEs at 5\% level of significance. Likewise, standardized beta coefficient exhibited that marketing factors followed by working premise and technological factor respectively were found the top three positive significance factors in the performance of the enterprises. Bothinferential sand descriptive findingrevealed that managerial and entrepreneur's factors were found the least determinant and problems for the growth of employment in the city adminstration. Whereas, infrastructure factors found to be moderately significance factor at $10 \%$ level of significance .
\end{abstract}

Keywords: MSEs, performance, factors

DOI: $10.7176 /$ RJFA/11-11-03

Publication date:June 30 th 2020

\section{Introduction}

The development of Small and Medium Enterprises (SMEs) is very crucial in economic development. The SME sector is important for the creation of employment, facilitation of broad-based development and the distribution of incomes. The SMEs classification is used to mean micro, small and medium enterprises. It is sometimes referred to as micro, small and medium enterprises (MSMEs). The SMEs cover non-farm economic activities mainly manufacturing, constriction, trade, service and urban agriculture. There is no universally accepted definition of SME. Different countries use various measures of size depending on their level of development. The commonly used yardsticks are total number of employees, total investment and sales turnover (Mhazo et al, 2011).

SMEs in Africa play vital roles in the community such as job creation, where current trends show that SMEs in Africa create over $80 \%$ of employment (IMF, 2015). IMF report further states that "over the next 20 years sub Saharan Africa will become the main source of new entrants in to the global labor force". Other roles of SMEs are reduction of poverty and development of local and regional integration. Despite of all roles played by SMEs in Africa still facing challenges which hinder them in their performance such as the access to finance. Most of SMEs in Africa fail to secure loans to the microfinance due to lack collateral security required by microfinance. Also, SMEs have low access to market, poor management skills and location (IMF, 2015).

Nowadays, in developing countries like Ethiopia, micro \& small enterprises are small informally organized business operations owned and operated mostly by the poor. They account for a substantial share of the total employment and gross domestic product (GDP) contribute significantly to the alleviation of poverty and income creation. They are often the chief economic cover of the most vulnerable households in high-risk environment, such as civil conflict, natural disasters and recurrent drought (Mulhern, 1995).

In November 1997 the Ethiopian Ministry of Trade and Industry (MoTI) published the "Micro and Small Enterprises Development Strategy: MSEDS", which enlightens a systematic approach to alleviate the problems and promote the growth of MSEs. Following the publication of MSE development strategic document, the government of Ethiopia set up Federal Micro and Small Enterprise Development Agency (FeMSEDA). The regional states also developed MSE promotion strategies based on prevailing situation with the federal MSEDS so that the states structured Regional Micro and Small Enterprises Development Agencies (ReMSEDAs) to facilitate implementation of the strategies.

However, implementation of the strategy is confronted with a number of factors. The major factors include among others financial problems, lack of qualified employees, lack of proper financial records, marketing problems, lack of work premises, lack of infrastructures and information (Admasu, 2012).. Personal attitudes, training and technical experience are also coined as major challenges (Werotew, 2010). 
Even with the aforementioned challenges ,the Ethiopian government provide due attention for micro and small manufacturing sectors to play their role in the efforts made to ensure economic transformation and realizing the vision to achieve middle income countries. Subsequently, Diradawa administration is cascaded its share to the efforts of the country to achieve the vision

\subsection{Statement of the Problem}

The Mses sector is believed as an engine of economic growth, poverty reduction, and social development owing to its consequence on reduction of unemployment, poverty reduction and income generation (IMF, 2015)). Likewise, MSEs Strategy in Ethiopia is also implemented to achieve it According to Dire Dawa Administration MSEs Development Agency 2018/2019 final report revealed that , small manufacturing enterprises had been still remained little in its job creation as compared to others MSCs sectors since 2009. By the same report it was also indicated that, out of the five MSEs Sectors (namely manufacturing, constriction, trade, service and urban agriculture), service and trade sectors created high job opportunity accordingly.

Previously, Admasu Abera (2012), conducted research at Arada and Lideta SubCities, ddis Ababa on factors affecting the performance of micro and small Manufacturing enterprises, the study was used profitability index of measuring the performance (the dependent variable) of MSEs and used micro and small enterprises as a target of conducting the research .

.Kinyua(2014),conducted a research objectively to investigate on factors affecting the performance of small and medium enterprises in the Jua Kali sector Nakuru town in Keny.

The study was used Ologit and micro and small enterprises as a target of conducting the research.Solomon Worku(2004), carried out research on socio economic determinants of small manufacturing enterprises ' growth at Addis Ababa, used multiple regression model and 14 dummy independent variables to study the research and also, used CAGR.

This research is conducted to fill the methodological and the target gap of the aforementioned study. That is to say, the researcher differ on using manufacturing enterprise as a target and compound average growth rate to measure the performance (dependent variable) variable

\subsection{Objective of the Study}

\subsubsection{General Objective of the Study}

to analyze factors that are affecting the performance of small manufacturing enterprises in the context of Dire Dawa city administration.

\subsubsection{Specific objectives}

$>$ To asses internal and external factors that affect the performance of small manufacturing enterprises

$>$ to examine the significant influence of each factors on the performance of small manufacturing enterprises

\subsection{Research Questions}

$>$ What are the internal and external factors that affect the performance of small manufacturing enterprises in the city administration?

$>$ What are the factors that are highly and poorly affecting the performance of small manufacturing enterprises?

\section{Literature Review}

According to MSE strategy regulation article (2011), micro enterprise entails the total capital excluding building, not exceeding Birr 50,000 in the small enterprises as an enterprise having a total capital, excluding building from Birr 50,000 to 500,000 in the case of service sector or Birr 100,000 to 1,500000 in the case of industrial sector and engaged 6 to 30 workers case including the owner, his family members and other employees. The case of service sector or not exceeding Birr 100000 in of industrial sector and engaged 5 workers including the owner, his family members and other employees. The same article defines aforementioned classification summarized with table 12 as:

\begin{tabular}{|l|l|l|l|}
\hline Type of enterprises & Sector & Human power & Asset \\
\hline \multirow{2}{*}{ Micro enterprises } & Industry & $\leq 5$ & $\leq 100000(\$ 6000$ or E4500) \\
\cline { 2 - 4 } & Service & $\leq 5$ & $\leq 50,000(\$ 3000$ or E2200) \\
\hline \multirow{2}{*}{ Small enterprises } & Industry & $6-30$ & $\leq$ birr 1.5 million $(\$ 9000$ or E70000) \\
\cline { 2 - 4 } & Service & $6-30$ & $<$ birr $500,000(\$ 30000$ or E 23000$)$ \\
\hline
\end{tabular}

According to the ISIC classifications (ISIS Revision-3 cited in CSA 2003), small manufacturing enterprises (which this study also follows) which use power driven machines, involve industrial groups or business types such as:-

$>$ manufacture of food products: manufacture of vegetable and animal oils and fats,

$>$ Made up textile articles, manufacture of carpets and rugs; manufacture of wearing Apparel, dressing and 
dyeing of fur;

$>$ manufacture of leather, manufacture of luggage, hand bags and foot wear;

$>$ manufacture of wood and products of wood and cork ;

$>$ manufacture of paper and paper products; publishing, printing and production of Recording

$>$ manufacturing of chemicals and chemical products;

$>$ manufacturing of other non metallic mineral products(manufacture of glass and glass Products, manufacture of ceramic and clay products, manufacture of articles o Concrete, cutting, shaping and finishing of stones;

$>$ Manufacture of fabricated metal products, except machinery and equipment; Manufacture machinery and equipment manufacture of parts and accessories for motor , Vehicles and their engines, and

$>$ Manufacture of furniture and manufacture jewelry and related articles.

$>$ Other manufacturing enterprises not elsewhere mentioned.

\section{Theoretical Perspective on Factors Affecting Performance of Micro and Small Enterprises Law of Proportionate Effect}

Gibrat (1931) developed a theoretical model to measure the relationship between firm growth and its initial size Gibrat's Law, or the "Law of Proportionate Effect," states that firm growth is independent on initial size. While, the outcome of other studies do not, even support a negative relationship between growth and size and substantiate that smaller and younger firms grow faster than larger firms Pasanen(2007).

\section{Theory of the Growth of the Firm}

In the book, The Theory of the Growth of the Firm, Edith Penrose (1959) offered some strong principles governing the growth of firms and the rate at which firms can grow successfully. She claimed that firms are a bundle of internal and external resources that help a firm to grow and to realize a competitive advantage. According to Penrose, firm size is minor to the growth process, whereas firm growth is determined by the effective and innovative managerial resources within the firm. She further explained that the availability of top managerial and technical talent serves as an engine to a firm's growth. Penrose has also suggested that ignorance of these factors results in failure and loss of competitive advantage of enterprises.

\section{Performance Measurement Theories Of Small Businesses}

According to Liedholm and Mead (1999), there are three ways of defining employment growth performance. These are annual compound growth rate and average annual growth rates measured in percent and average annual growth in employment since start up measured in number of jobs created. The compound annual growth rate (CAGR) is a rate of growth that tells what an enterprise growth in employment over the years on an annually compounded basis is measured in percent.

\section{Empirical Literature}

According to Admasu Abera (2012), the study conducted at Arada and Lideta Sub-Cities, Addis Ababa on small enterprises ,he found that financial, working premise and marketing factors were the prime external causes affecting the performance of small manufacturing enterprises respectively. Besides, he found that entrepreneurial and management factors were found to be the least internal factors affecting the performance of manufacturing small business (8th and 5th factors respectively).He also pointed out that there is appositive relationship and a strong correlation among the variables

According to Arya Solomon(2015), the study conducted on factors affecting the performance of micro and small enterprises in Hawssa,he found that access to infrastructure (access water ,electric power and transport service), access to working premise and access to finance are the prime causes for the failure of firms.

Based on MUDC (2013), is the first of its kind in Ethiopia was conducted by ministry of urban development and construction on Micro and Small Enterprises (MSEs), aiming at identifying a number of challenges and constraints hindering the growth of MSEs in Selected Major Cities of Ethiopia. These challenges were manifested in terms of capital, technology and employment growth trends. Enterprises from the regional cites indicated that shortage of finance (42 percent) to expand their business was their principal challenge, followed by lack of working premise (28.3 percent); and lack of access to market or absence of linkage to 


\section{Conceptual Framework of the Study}

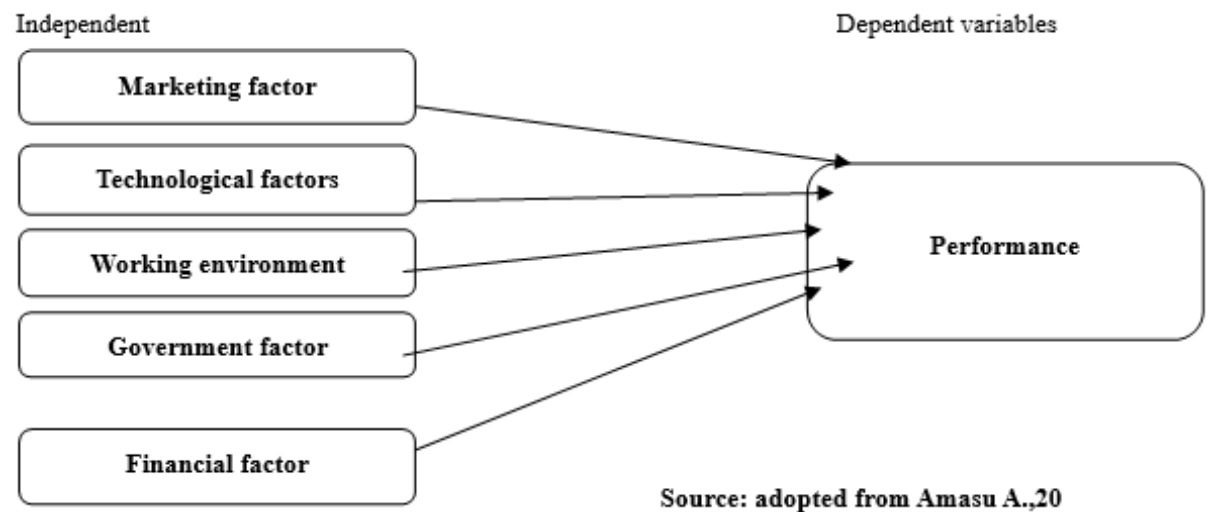

\section{Research Methodology}

Research Design: The research design that was used for the study is descriptive and explanatory research design. Since the purpose of explanatory research design is to explain and interpret the relationships between two or more aspects of variables or phenomenon, For the purpose of this study, the researchers combine both quantitative and qualitative research methods for triangulation. Consequently, the use of the triangulation approach is to crossverify the collected data and/or information from two or more sources. Generally, the researchers used key informant interviews, observations and structured questionnaires to gather the required data from sample respondents of the selected enterprises

Sources of Data: The study employed both primary and secondary data sources. Primary data was collected from manufacturing small enterprises, use of structured five point likert scale questionnaire, interview, focus group discussion and observation. The secondary data was collected by reviewing relevant documents, related journals and published and unpublished articles, different electronic search engine such as the internet, and other published materials about the research topic.

Sampling Methods: stratified and systematic sampling was employed to select the representative. In this study a sample of 222 small enterprises were selected out of a total of 500 based on systematic sampling. With regard to the sample size, the researcher applied a simplified formula provided by Yamane (1967) to determine the minimum required sample size at $95 \%$ confidence level, degree of variability $=0.5$ and level of precision $(\mathrm{e})=5 \%$

$\mathrm{n}=\frac{\mathrm{N}}{1+\mathrm{N}}$

$\overline{1+\mathrm{N}}(\mathrm{e})^{2}$

Where $\mathrm{n}$ is sample size, $\mathrm{N}$ is the total number of study population, 2043 ; Where e is the level of precision

\section{Data Analysis Methods}

In this study, before processing the responses, data preparation was carried out on the completed questionnaires through editing, coding, transcribing (entering), and cleaning the data. Descriptive analysis using measures of central tendency was used such as; mean median and mode, as well as measures of variability such as the standard deviation and variance to determine the proportions and frequency of the variables. Spearman's Correlation and multiple regression models as well as $\boldsymbol{X}^{2}$ were used to establish the relationship and strength between the dependent and independent variables. Data analysis was done using tools namely; Statistical Package for Social Scientist (SPSS version 21) as well as STATA version 14. . The qualitative data obtained from key informants, and data obtained from document review was analyzed through multiple response methods. The study results was presented in the form of figures and tables.

For the purpose of measuring internal consistency of the scales, Cronbach's alpha coefficient of correlation was used. The qualitative responses from semi-structured interviews with key informants, observations and documentary analyses was translated and analyzed using thematic analysis techniques. Afterwards, the qualitative findings was presented theme by theme in order to triangulate the findings of the quantitative aspect of the study. Model Specification: $Y i=\beta 0+\beta 1 X I i+\beta 2 X 2 i+\beta 3 X i+\beta 4 X 4 i+\beta 5 X 5 i+\beta 6 X 6 i+\beta 7 X 7 i+\beta 8 X 8 i+€ i$

Where, $\mathrm{Yi}$ is the dependent variable- performance of manufacturing small enterprises $(\mathrm{P})$

$\mathrm{X} 1=$ government rules and regulations(GRAR) ,X2= working premises(WP), $\mathrm{X} 3=\operatorname{technology}(\mathrm{T}), \mathrm{X} 4=$ infrastructure(I), X5= marketing(MA), X6= finance(F), X7= management(M) and X8= entrepreneurial skills(E) are the explanatory variables while $€$ is a random variable 


\section{Result and Discussion}

\section{Regressions Analysis}

Under this include information about mode summery, goodness fit of the model, variance inflation factor andthe quantity of variance that is explained by independent variable. The results of such analysis are narrated under.

\begin{tabular}{|c|c|c|c|c|c|c|c|c|}
\hline \multirow{2}{*}{ 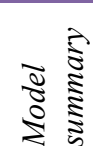 } & $R$ & & Adjusted $R$ & \multicolumn{2}{|c|}{ Std. Error of the Estimate } & Sig. & \multirow{4}{*}{ VIF } & \multirow{4}{*}{ Rank } \\
\hline & .877 & .768 & .712 & \multicolumn{2}{|l|}{.186} & .000 & & \\
\hline \multirow{11}{*}{ 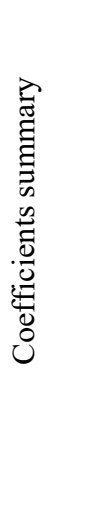 } & Model & \multicolumn{2}{|c|}{$\begin{array}{l}\text { Un standardized } \\
\text { Coefficients }\end{array}$} & $\begin{array}{l}\text { Standardized } \\
\text { Coefficients }\end{array}$ & \multirow[b]{2}{*}{$\mathrm{T}$} & \multirow[b]{2}{*}{ Sig. } & & \\
\hline & Variables & B & Std. Error & Beta coefficients & & & & \\
\hline & Constant & -153.01 & .276 & - & -5.551 & $.000^{*}$ & - & \\
\hline & $\begin{array}{l}\text { Government rule } \\
\text { and regulation }\end{array}$ & 7.594 & .050 & .141 & 1.509 & .141 & 1.252 & - \\
\hline & Working premises & 21.655 & .060 & .345 & 3.580 & $.001^{*}$ & 1.321 & $2^{\text {nd }}$ \\
\hline & Technological & 12.627 & .042 & .270 & 3.033 & $.005^{*}$ & 1.126 & $3^{\text {rd }}$ \\
\hline & Infrastructural & 8.494 & .047 & .162 & 1.799 & .081 & 1.151 & $5^{\text {th }}$ \\
\hline & Marketing & 28.899 & .047 & .571 & 6.166 & $.000^{*}$ & 1.221 & $1^{\mathrm{st}}$ \\
\hline & Financial & 9.615 & .047 & .201 & 2.058 & $.048^{*}$ & 1.359 & $4^{\text {th }}$ \\
\hline & Management & -1.260 & .036 & -.032 & -.353 & .726 & 1.138 & - \\
\hline & Entrepreneurial & .681 & .057 & .011 & .120 & .905 & 1.228 & - \\
\hline
\end{tabular}

Table above displays the estimates of the multiple regression of performance against its variables, goodnessof-fit of the model and the output of ANOVA for the 42 small manufacturing enterprises. The first model summary, statistic, R, is the multiple correlation coefficients between all of the independent variables and the performance. In this model, the value is 0.877 . The next value, $\mathrm{R}$ Square, is simply the squared value of $\mathrm{R}$. This is frequently used to describe the goodness-of-fit or the amount of variance in performance explained by given set of predictor variables. In this model, the value is 0.768 , which indicates that $76.8 \%$ of the variance in performance of small manufacturing enterprises is explained by the independent variables. Similarly, under this model summery ANOVA describes the overall variance accounted for in the model. The F statistic represents a test of the null hypothesis that the regression coefficients are all equal to zero. In this model all the null hypothesis for marketing, working, finance and technology are different from zero and p-value $(0.000)$ would indicate that there is a linear relationship. In the second coefficients summery, the un standardized coefficients B column, gives us the coefficients of the independent variables. Independent variables which determine the growth of employment at $5 \%$ level of significance are summarized below as:

$\mathrm{Yi}=-153.017+21.655 \mathrm{X} 1 \mathrm{i}+12.627 \mathrm{X} 2 \mathrm{i}+28.899 \mathrm{X} 3 \mathrm{i}+9.615 \mathrm{X} 4 \mathrm{i}$

Where, $\mathrm{Yi}=$ Predicted performance, $\mathrm{X} 1 \mathrm{i}=$ working premises, $\mathrm{X} 2 \mathrm{i}=$ technological, $\mathrm{X} 3 \mathrm{i}=$ marketing and $\mathrm{X} 4 \mathrm{i}=$ finance

The above table, similarly shows that, the four explanatory variables mentioned above included in this study can significantly explain at $95 \%$ confidence level to the variation on the performance. as well ,infrastructure factor moderately significant at $90 \%$ confidence level.

The standardized beta coefficient column shows that data expressedin standardized, or $\mathrm{z}$ score form. Thus, significant independent variables have a mean of zero and a standard Deviation of one and are thus expressed in the same units of measurement. In this regard, the beta coefficient is the average amount that dependent variable increases when the independent variable increases by one standard deviation (all other independent variables are held constant). Once, these are standardized there have a room to compare the influence of each independent variables on performance. Thus, the largest influence on the performance is from the marketing factor (.571) and followed by working premises factor (.345).and technological factor (.270) respectively.From above one can conclude that both internal factors i.e., entrepreneurial and management factors have insignificance influence on the performance of MaSEs in the city administration.

To sum up,summary of results and discussions based on inferential and descriptive results were worth drawn below as:-

- Marketing factors: -In the regressions analysis marketing factors was identified as the leading positive significant influential factors ofMaSEsin the city administration at $1 \%$ level of significance. This shows that the factor is decisive for employment growth and a one standard unit increase in marketing factores results in .571 increase in performance while keeping other variables constant. Correlation results was also shown that there is a strong relationship $(0.6$ to 1.00$)$ between the factors and performance $(r=.741, p<.05)$.In this research output, the descriptive findings of the factors likewise exhibited as the prime problem that contributing a considerable influence on the performance of MaSEs in the city administration. Under this factor, inadequacy of market, difficulty of searching new market and lack of demand forecasting respectively was found severe problems that 
challenging the MaSEs (table 4.9).In contrary with this finding, Haftu Berihun et al. (2009) and Admasu Abera(2012) found that marketing factors were the third significance influential factors affecting the performance of the enterprises and ranked descriptively as third severe problems.

- Working premise factors: -In the above regression output,working premise factors was found the second most positive significant and determinant factor for employment growth at $1 \%$ level of significance. This indicates that the factor is substantial for employment generation in MaSEs sector and a one standard unit increase in working factors results in .345 in performance while keeping other variables constant. A correlation result also revealed that there is a medium relationship between the factors and performance $(r=.325, p<0.05)$. The descriptive results of this factor as well revealed as the second severe problems of MaSEs. This shows that the factors posed a major problem for the growth of employment in GTP1 period. Under this factor, absence of own premises, the rent of house is too high and the current working place is not convenient for the business respectively were found the leading challenges of the MaSEs (table 4.9).In contrary with the findings, Haftu Berihun et al. (2009) and Admasu Abera(2012) found that working premise factors were the first most significant influential factors affecting the performance of the enterprises and ranked descriptively as the second most affecting problems but in consistency with the items as mentioned above.

- Technological factors:- In the regression summery model ,technological factors found to be the third most positive significance and determinant factor 5\% level of significance. The result pointed out that the factor is crucial for employment generation and a one standard unit increase in technological factors results in .270 increase in performance while keeping other variables constant. In descriptive analysis ranked as the fifth severe problems of the enterprises. Along with it, lack of money to acquire new technology and lack of appropriate machinery and equipment respectively were found the core problems that challenging MaSEs(table 3.9).In contrary with the finding, Haftu Berihun et al. (2009) and Admasu Abera(2012) found that technological factors were seventh least significant influential factors and prioritized descriptively as seventh least affecting factors.

- Financial factors:-In table 4.11 regression summery, financial factors was found the fourth most statistically significance and determinant factor of employment generation at 5\%level of significance and a one standard unit increase in financial factor results in.201 increase in performance while keeping other variables constant. Similarly, the descriptive analysis ranked as the third severe problem that affecting the enterprises. This result showed that the factors contributed a significant problem for hindering the growth of employment in GTP1perod. This factor ranked Shortage of working capital, high collateral requirement from banks and other lending institutions and lack of cash management skill respectively coined as the key challenging issues of MaSEs(table 3.9). In contrary with this finding, Admasu Abera(2012) and Haftu Berihun et al. (2009) found that financial factors were the second most significant influential factors affecting the performance of the enterprises and prioritized descriptively as the first most affecting factors

- Infrastructure factors:-It was found as moderately significance for job generation of MaSEs at $10 \%$ level of significance. In descriptive analysis it was ranked as the six least problems that affecting MaSEs .Under this factor, power interruption, insufficient and interrupted water supply and lack of appropriate dry waste and sewerage system respectively were found the fundamental challenges of MaSEs. (Table 3.9). Admasu Abera(2012) found that infrastructure factors were the fourth most significant influential factors affecting the performance of the enterprises and prioritized descriptively as also the fourth most affecting problems.

- Government rule and regulation factors:-The multiple linear econometric results revealed that government rule and regulation factor is insignificance for employment growth of MaSEs. Descriptively, it was found the fourth challenging problems of MaSEs in GTP1 period. Under this factor, lack of accessible information on government regulations that are relevant to the business, the tax levied on the business is not reasonable and long bureaucratic chains, corruption, nepotism in getting service registration and licensing respectively were coined as the leading problems of MaSEs.Admasu Abera(2012) found that government rule and regulation factors were the six least significant influential factors affecting the performance of the enterprises and prioritized descriptively as also the six most affecting problems .

- Management factors:-The econometric result exhibited that this factor is statistically insignificant for employment generation in MaSEs sector. Based on results of central tendency and dispersions, it was ranked as the eighth least problem that confronting MaSEs. This similarly shows that the factor contributed insignificant influence on the performance of MaSEs in GTP1 period .Admasu Abera(2012) foundthe factor as the poorest predictor of performance and the fifth ranked problems of the enterprises. In contrary to the study, the Theory of the Growth of the Firm, Edith Penrose (1959) advocate that managerial resource is critical influential factor for business growth. Similarly, According to Peterson et al. (1983), two third small business failure is caused by internal factors ,however; in this study the failure of the business is largely accounted by external factors.

- Entrepreneurial factors:-Table 4.11 has shown that the factor is insignificantly affecting the growth of employment.This implies that the factor is not decisive determinant for the performance of MaSESs. Descriptively it was ranked as the seventh influential factor. This result implies the factor added insignificant influence on the 
growth of employment in GTP1period. In consistency with Admasu Abera(2012), it was found as a poor determinant of employment growth in the DDCA.

In consistency with the study ,Admasu Abera(2012) and Haftu Berihun et al. (2009) found that management, government rule and regulations and Entrepreneurial factor were the poorest predictor of performance and the least influential factors factors that affecting the performance of the enterprises respectively and prioritized descriptively as also the five, eight and six challenging problems.

In contrary to the research, Mekonnen Drbie \& Tilaye Kassahun(2013),found that infrastructure ,finance and managerial factors were the top three factors challenging the performance of MaSEs

\section{Conclusion and Recommendation}

\section{Conclusion}

This research was conducted in Diredawa city administration with the prime intent of critically assessing the factors affecting the growth of employment of manufacturing small enterprises engaged in garment, food processing, metal and wood work and, leather and shoe activities. Specifically, the study attempted to asses internal and external factors and ranking the estimating influence of factors on the performance of MaSEs. Based on the objectives and findings of the study, the following conclusions are worth drawn.

The descriptive analysis findings indicate that marketing, working premises, financial and government rule and regulation factors respectively were found the four top most prevailing severe problems that contributing a significant influence on the growth of employment in MaSEs sector in GTP1 period.

The econometric multiple regression analysis revealed that marketing, working premise, technological and financial factors are found the top most positive determinants of employment generation in the study area at $5 \%$ level of significance. Infrastructure factors also found to be moderately determinant factor of employment generation at $10 \%$ level of significance. Likewise, standardized coefficient results exhibit that marketing factors followed by working premise and technological factors were found the top three significance influential factors on the performance of the enterprises. Entrepreneurs and managerial factors were found to be insignificant determinants of employment generation and the least influential problems in the study area.

\section{Recommendation}

The findings of this study have important implications for interventions designed to enhance the growth and expansion of MaSEs in Diredawa city. In the study, it was found that job generation is mainly determined by marketing, working premise, technological and financial factors, a concerted attention should be given to those factors that determines the performance of enterprises. Such factors are identified and are reported in the results and discussion of the study. Recommendations based on the aforementioned determinants required an in-depth analysis of the influence of different other factors regarding the sector. Yet, the following recommendations are withdrawn.

Strengthening the relevant government institutions namely, dire microfinance institution ,cooperative office ,DDAMSEDA, trade and industry bureau ,kebele representatives of MSEs at different levels that to play their respective major role in positively influencing the development of manufacturing small enterprises, by jointly devising new systems that to address the top most severe problems that primarily challenges the determinant factors of employment generation. Specially, concerning government bodies should have a responsibility to reduce long bureaucratic chains, corruption and nepotism in getting services and providing up to date accessible information on government regulations and the like that are relevant to business.

Marketing, working premise and financial factors are frequently coined as thekey problems challenging the determinant factors of employment generation by the studied of small enterprises. Therefore, it is necessary to solve these deep-rooted problems of the enterprises by devising new rule and regulations, especially on issues that to address the problem of availability in independent production and selling place for the enterprises.

Prepare an incentive package for enterprises that take in to account of issues that to address the critical problems of the enterprises. The issues worth considering are: rules and regulations that allow an incentive for production and selling place for enterprises that can graduate to medium one and create more jobs than the expected period of time; allocating revolving founds for providing with a minimum loan to address their financial requirements for buying new technologies ;allowing enterprises to import new technologies with duty free incentives ; the concerning government bodies in particular assisting the enterprises to form groups and make use of pooled negotiating power for borrowing purposes. They can use such negotiating power to purchase raw materials and receive discounts which might lead to a reduction in the cost of production. In a nut shell, the city administration may play a pivotal role working on tackling the most severe problems identified by research to enhance employment generation in GTP2period.

\section{Reference}

Admasu,A. (2012).Factors affecting the performance of Micro and Small Enterprises in Arada and Lideta Sub 
-cities.Addis Ababa(Master's thesis),Adiss Ababa University

Arya,S.(2015).Factors affecting the performance of Micro and Small Enterprises.In Hawassa City, Ethiopia.

CSA.(2003).Report on Bi-Annual Employment Unemployment Survey ,1 st year Round 1,stastical Bulletin 319 :Federal Democratic Republic of Ethiopia (FDRE), Central Statistical Authority.

IMF. (2015). Challenges of Financing SMEs, Finance for All: Promoting Financial Inclusion in Central Africa, Brazzaville, Congo

Kinyuan, D. \& Quartey, P.(2000). The Policy Environment for Promoting Small and Medium-sized Enterprises in Ghana and Malawi.Paper No.15.Instituteof Development Policyand Management, University of Manchester. Available from http://www.man.ac.uk/idpm. [Accessed 2 February 2012].

Liedholm, Carl, and Mead, C. Donald.(1999). Small Enterprises and EconomicDevelopment:The Dynamics of micro and small enterprises, Rutledge Studies in Development Economics, New York

MoUDC.(2013).Survey on Micro and Small Enterprises (MSEs)in selected majorities of Ethiopia .Addis Ababa :Federal democratic Republic of Ethiopia Ministry of Trade and Industry.

Mhazo, N., Brighton, M., Nyakudya, E., and Raymond M.(2011). The status of the agro-processing industry in Zimbabwe with particular reference to smalland medium-scale enterprises, Harare, Zimbabwe

Mulhern D. (1995). Entrepreneurship and management. Journal of Small Business Management, 25(3):92.

Pasanen, M.(2007). SME growth strategies: organic or non-organic? J. Enterprising Culture, 15(317). DOI:10.1142/S0218495807000174. Department of Business and Management, University of Kuopio, Finland

Peterson, R.A.,G. Kozmetsky and N. M. Ridgway. (1983). Perceived Causes of Small Business Failures: A Research Note, American Journal of Small Business, 8(1):15-19.

Werotew Bezabih Assefa. (2010): Entrepreneurship: An Engine for Sustainable Growth, Development, prosperity and Good Governance; Genius Training and Consultancy Service, Addis Ababa, Ethiopia.

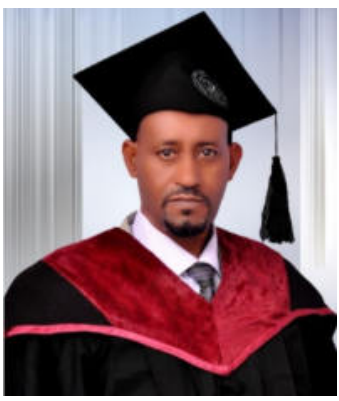

Abiy Serawitu Kassaye

Senior consultant at Dire Dawa

Management and Kaizen Institute

(PhD Candidate) 